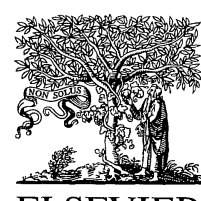

ELSEVIER

Contents, Volume 6

No. 1

September 1994

\title{
Editorial
}

Antifertility vaccines: the wrong road?

N. Wieringa (Netherlands)

\section{Regular Papers}

Gynecological chair syncope in elderly women: practical implications for general practitioners and gynecologists

A. Schoenfeld, M. Rosenblatt, A. Neri and J. Ovadia (Israel)

Chronic lead exposure and pregnancy

C. Savona-Ventura, M. Sammut, G. Ducoffre and F. Claeys (Malta, Belgium)

Biological aspects of root filling therapy in dentistry

B. Fredin (Sweden)

Are percutaneous transluminal coronary angioplasty and coronary artery bypass grafting safe enough?

B.A. De Mol and F. Koornneef (Netherlands)

Towards a model on prevention of errors in general practice M.C.J. Schuling, M. De Bruijn and B. Meyboom-de Jong (Netherlands)

Medical negligence litigation in Britain: current flaws and possible alternatives

P. Hoyte (UK)

Forthcoming Meetings and Courses 
No. 2

November 1994

Malformation surveillance and maternal drug exposure: the MADRE project E. Robert, S.E. Vollset, L. Botto, P.A.L. Lancaster, P. Merlob, P. Mastroiacovo, G. Cocchi, M. Ashizawa, S. Sakamoto and I. Orioli (France, Norway, Italy, Australia, Israel, Japan, Brazil)

Preventing intraoperative complications: a new monitoring device for intraoperative EEG recordings A. Schultz, B. Schultz, U. Grouven, G. Aselmann, F. Bergel and I. Pichlmayr (Germany)

Patients' willingness to accept risk of medical treatments D.J. Mazur and D.H. Hickam (USA)

The Danish Patient Insurance Act of 1991: first experiences M. Broberg (Denmark)

Review

Cervical manipulation: is it really safe?

E. Ernst (UK)

Forthcoming Meetings and Courses

151

No. 3

February 1995

Editorial

Is pharmacovigilance still a clinical science?

K. Kimbel (Germany)

Regular Papers

What can be done to improve the safety of heart valves?

B.A.J.M. De Mol, F. Koornneef and G.L. Van Gaalen (Netherlands)

A new technique for increasing the quality of composite fillings in dentistry creating a superior alternative to dental amalgam B. Fredin (Sweden)

Inadequate drug information for pregnant or lactating women: teratology information service follow-up

P. Merlob, B. Stahl, A. Schoenfeld and B. Kaplan (Israel)

The risks of acupuncture

E. Ernst (UK) 
Short Report

Arteriovenous fistula: a complication of venous puncture at the elbow M. Wolf, O. Maitre, G. Calio and P. Martin (France)

Profile

INRUD: the International Network for Rational Use of Drugs

Hippocrates

Safety \& Risk in Practice

\section{Book Reviews}

Home health care law

Guidelines for clinical practice guidelines

How to break bad news

Forthcoming Meetings

Contents of Volume 6 